2. Arez AP, Snounou G, Pinto J, Sousa CA, Modiano D, Ribeiro H, et al. A clonal Plasmodium falciparum population in an isolated outbreak of malaria in the Republic of Cabo Vorde. Parasitology 1999;118:34755.

3. Mungai M, Tegtmeier G, Chamberland M, Parise M. Transfusion-transmitted malaria in the United States from 1963 through 1999. N Engl J Med 2001;344:1973-8.

4. Slinger R, Giulivi A, Bodie-Collins M, Hindieh F, St. John R, Sher G, et al. Transfusion-transmitted malaria in Canada. CMAJ 2001;164:377-9.

5. Benito A, Rubio JM. The usefulness of the seminested malaria-PCR to screen blood donors at risk in Spain. Emerg Infect Dis 2001;7:1068.

6. Zucker JR. Changing patterns of autochthonous malaria transmission in the United States: a review of recent outbreaks. Emerg Infect Dis 1996;2:37-43.

\section{Rickettsia aeschlimannif: A New Pathogenic Spotted Fever Group Rickettsia, South Africa}

To the Editor: Spotted fever group rickettsiae are increasingly recognized as agents of disease in residents of and tourists to South Africa (1). To date, two species, Rickettsia conorii and $R$. africae, which cause Mediterranean spotted fever (MSF) and African tick-bite fever (ATBF), respectively, have been associated with human disease in the region; ATBF is more frequently associated with travel (1). As different antibiotic regimens are recommended for the two syndromes, differentiating MSF from ATBF is important. Increasing evidence shows that the syndromes can usually be differentiated through clinical manifestations and epidemiologic characteristics (1).

We recently encountered a South African patient who, on returning from a hunting and fishing trip, discovered a Rhipicephalus appendiculatus tick attached to his right thigh and an eschar around the attachment site. The patient was aware of the risk of tick-transmitted disease; after removing the tick, immediately self-prescribed doxycycline. No further symptoms developed. However, as a precaution, the patient went to a local clinic, where a skin biopsy was taken from the eschar. This sample, together with the removed tick, was submitted to our laboratory. DNA extracts, prepared from an eschar biopsy and the tick, were incorporated into a polymerase chain reaction (PCR) assay specifically targeting a fragment of the rickettsial ompA (2). Sequence analysis of the amplification products showed both to be identical and to share $>99 \%$ similarity with the ompA of $R$. aeschlimannii, a species not previously associated with human disease. Unfortunately, blood samples could not be collected at the time the patients first had symptoms; thus, investigation of a disseminated infection by PCR and serologic testing was not possible.

Although genotypically indistinguishable organisms had previously been detected in Hyalomma marginatum collected in Portugal and Zimbabwe, $R$. aeschlimannii was first characterized following its isolation from $H$. marginatum ticks in Morocco (3) and recently in Niger (4). This encounter was the first demonstration of its presence in South Africa and in Rhipicephalus ticks.

A lack of suitable clinical material prevented full evaluation of the pathogenic potential of $R$. aeschlimannii in this patient and prompt antibiotic intervention may have prevented evolution of the syndrome. Nonetheless, that $R$. aeschlimannii was transmitted to the patient and established a local infection leading to eschar formation provides clear, albeit preliminary, evidence of its virulence. Until further cases are encountered, allowing better characterization of the clinical manifestations associated with $R$. aeschlimannii infection and considering the agent capable of inducing either MSF or ATBF-like manifestations is cru- cial; neither of these syndromes can be associated with a specific causative agent without microbiologic identification. Our findings demonstrate that Rickettsia species first encountered in tick surveys are associated with human disease, and we should not assume that some Rickettsia species not have a pathogenic potential.

\section{Anne-Marié Pretorius* and Richard J. Birtles†}

*University of the Free State, Bloemfontein, South Africa and HUniversity of Liverpool, Liverpool, England

\section{References}

1. Raoult D, Fournier P-E, Fenollar F, Jensenius M, Prioe T, De Pina JJ, et al. Rickettsia africae, a tick-borne pathogen of travelers to sub-Saharan Africa. N Engl J Med 2001;344:1504-10.

2. Roux V, Fournier P-E, Raoult D. Differentiation of spotted fever group rickettsiae by sequencing and analysis of restriction fragment length polymorphism of PCR amplified DNA of the gene encoding the protein rOmpA. J Clin Microbiol 1996;34:205865.

3. Beati L, Meskini M, Thiers B, Raoult D. Rickettsia aeschlimannii sp. nov., a new spotted fever group rickettsia associated with Hyalomma marginatum ticks. Int J Syst Bacteriol 1997;47:548-54.

4. Parola P, Inokuma H, Camicas J-L, Brouqui P, Raoult D. Detection and identification of spotted fever group rickettsiae and ehrlichiae in African ticks. Emerg Infect Dis 2001;7:1014-7.

\section{Age as a Risk Factor for Cutaneous Human Anthrax: Evidence from Haiti, 1973-1974}

To the Editor: Few cases of anthrax have been reported in children, in part because most exposures to Bacillus anthracis occur in workplace settings. Questions about the susceptibility of children to $B$. anthracis infection were raised when cutaneous anthrax developed in a 7-month- 
old child in New York City in 2001 after he was taken to visit his mother's workplace (1). No cases of anthrax were reported in persons $<24$ years of age in the 1979 inhalational anthrax outbreak in the Soviet city of Sverdlovsk, despite a presumed general population exposure (2). Such reports have led some investigators to postulate that young persons may be less susceptible to anthrax than older persons.

In 1974, the Center for Disease Control reviewed records on the occurrence of human anthrax in District Sanitaire des Cayes, Haiti, as part of an investigation of cutaneous anthrax in a Florida woman exposed to spore-contaminated goatskin drums she purchased in Haiti (3). In 1973, a total of 387 cases ( 7.6 per 10,000 population) were clinically diagnosed in District Sanitaire des Cayes; another 59 cases occurred in the first 4 months of 1974. All cases were the cutaneous form; gastrointestinal and inhalational anthrax are rarely, if ever, diagnosed in Haiti. The source of infection in these 446 patients could not be deter- mined. Although cases of animal anthrax were rarely reported in Haiti because of a weak surveillance system, $96(26 \%)$ of 368 Haitian goatskin handicraft items were found to be contaminated with $B$. anthracis during the 1974 investigation, suggesting that animal infections were not uncommon (4). Therefore, the source of the infection may have been meat and other products of value salvaged by local residents from anthrax-infected animals.

Age was reported for 366 of the 446 patients in District Sanitaire des Cayes (Table). The distribution of anthrax cases by age group was generally similar to that of the general population, except the proportion of cases in the 15- to 44-year age group was lower than the proportion of persons in that age group in the general population ( $<<0.03$; chi square). In 124 patients for whom information was available, the cutaneous lesion was located on the head or neck $(60$ patients $[48 \%])$, the arm (31 [25\%]), the trunk (23 [19\%]), and the leg (12 $[10 \%]$ ); this anatomic distribution,

Table. Reported ages of persons with cutaneous anthrax, District Sanitaire des Cayes, Haiti, 1973-74

\begin{tabular}{lccc}
\hline Age group (yrs) & $\begin{array}{c}\text { Anthrax patients } \\
\text { No. (\%) }\end{array}$ & $\begin{array}{c}\text { General population } \\
\text { No. (\%) }\end{array}$ & Cases per 10,000 persons \\
\hline$<1$ & $15(4.1)$ & $16,361(3.2)$ & 9.2 \\
$1-4$ & $49(13.4)$ & $59,291(11.6)$ & 8.3 \\
$5-14$ & $96(26.2)$ & $120,532(23.5)$ & 8.0 \\
$15-44$ & $135(36.9)$ & $235,164(45.8)$ & 5.7 \\
$45-64$ & $58(15.8)$ & $64,882(12.7)$ & 8.9 \\
$\geq 65$ & $13(3.6)$ & $16,669(3.2)$ & 7.8 \\
All ages & 366 & 512,899 & 7.1 \\
\hline
\end{tabular}

reflecting the primary skin contact point of the organism, was similar in all age groups. However, determining whether the various age groups had differences in skin contact exposure leading to infection is difficult. The affected rural population lived in extreme poverty, typically in small huts with dirt floors and no safe water supply or latrine. Malnutrition was epidemic, and nothing edible was discarded. The crowded living conditions limited opportunities to maintain basic personal hygiene and made it likely that exposure to B. anthracis-contaminated materials was similar across all age groups. These previously unpublished age-specific anthrax attack rates from Haiti suggest that adults and children have similar susceptibility to cutaneous anthrax.

\section{Arnold F. Kaufmann and Andrew L. Dannenberg}

Centers for Disease Control and Prevention Atlanta, Georgia, USA

\section{References}

1. Centers for Disease Control and Prevention. Update: investigation of anthrax associated with intentional exposure and interim public health guidelines, October 2001. MMWR Morb Mortal Wkly Rep 2001;50:889-93.

2. Meselson M, Guillemin J, Hugh-Jones M, Langmuir A, Popova I, Shelokov A, et al. The Sverdlovsk anthrax outbreak of 1979. Science 1994;266:1202-8.

3. Center for Disease Control. Cutaneous anthrax acquired from imported Haitian drums-Florida. MMWR Morb Mortal Wkly Rep 1974;23:142,147.

4. Center for Disease Control. Follow-up on cutaneous anthrax acquired from imported Haitian drums-Florida. MMWR Morb Mortal Wkly Rep 1974;23:224.

Guidelines for Letters. Letters discussing a recent Emerging Infectious Diseases article (400-500 words, 5-10 references) should be received within 4 weeks of the article's publication. Letters reporting preliminary data (500-1,000 words, 10 references) should not duplicate other material published or submitted for publication, should not be divided into sections, and should avoid figures or tables. All letters have the same authorship, financial disclosure, and acknowledgment requirements as full articles and should include a word count. For more guidance on manuscript preparation, see Emerging Infectious Diseases Instructions to Authors. Send letters to the Editor, Emerging Infectious Diseases, Centers for Disease Control and Prevention, 1600 Clifton Rd., MS D 61, Atlanta, GA 30333, USA, or e-mail: eideditor@cdc.gov.

Letters Editor: Patricia M. Quinlisk, Des Moines, Iowa, USA

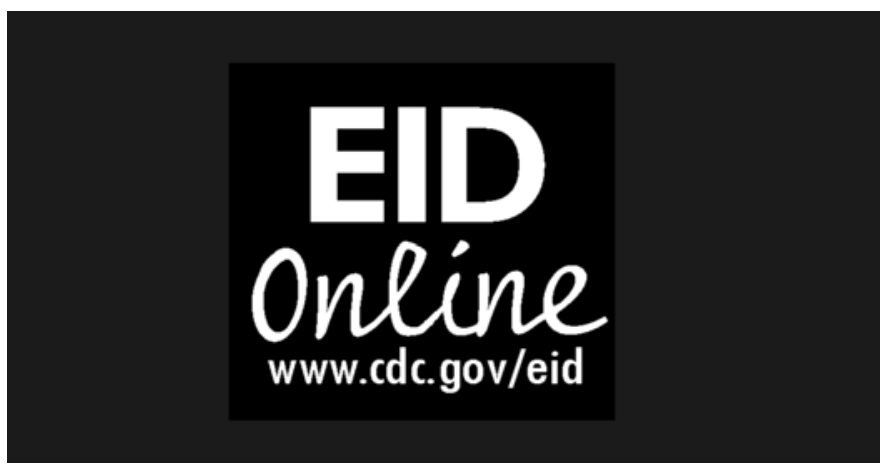

